\title{
Diagnosis of Premature Rupture of Membranes by the Detection of Thyroid Hormones in Vaginal Secretions
}

\author{
Mandana Rashidi, ${ }^{1}$ Shaghayegh Barzegar, Zahra Najmi, ${ }^{2, *}$ and Ladan Haghighi ${ }^{1}$ \\ ${ }_{1}^{1}$ Department of Obstetrics and Gynecology, Shahid Akbar-abadi Hospital, Iran University of Medical Sciences, Tehran, IR Iran \\ ${ }^{2}$ Department of Obstetrics and Gynecology, Endometriosis Research Center, Rasoul-e-Akram Hospital, Iran University of Medical Sciences, Tehran, IR Iran \\ *Corresponding Author: Zahra Najmi, Department of Obstetrics and Gynecology, Endometriosis Research Center, Rasoul-e-Akram Hospital, Iran University of Medical Sciences, Teh- \\ ran, IR Iran. Tel: +98-216651500, Fax: +98-2166509283, E-mail: zahranaj@yahoo.com
}

Received 2015 May 29; Revised 2015 September 15; Accepted 2015 October 15.

\begin{abstract}
Background: Premature rupture of membranes (PROM) and preterm PROM (PPROM) are the rupture of the fetal chorioamniotic membranes before the onset of labor contractions.

Objectives: To evaluate whether detection of thyroid hormones in vaginal washouts can be used to diagnose premature rupture of membranes(PROM).

Patients and Methods: Total T4 (thyroxin), total T3 (triiodothyronine), and free T4 concentrations in vaginal washouts were analyzed in 45 women with the diagnosis of PROM and compared with 45 normal pregnancies (controls). A Student's t-test was used for comparison of thyroid hormone values and a ROC curve was used for analyzing the diagnostic accuracy.

Results: There were no differences between the patients with PROM and the control women regarding maternal age, gestational age, and parity. The mean concentration of total T4 in the PROM group and the control subjects were $2.1 \pm 1.3 \mu \mathrm{g} / \mathrm{mL}$ and $1.55 \pm 0.58 \mu \mathrm{g} /$, respectively $(\mathrm{P}=0.01)$. Total T3 concentration in the PROM group was significantly higher compared to the controls $(1.28 \pm 0.42 \mathrm{ng} / \mathrm{vs} .0 .8 \pm 0.26 \mathrm{ng} /, \mathrm{P}<$ 0.0001). Also, free T4 concentration was significantly higher in the PROM group as compared with the controls $(0.026 \pm 0.034 \mathrm{ng} / \mathrm{vs} .0 .007$ $\pm 0.004 \mathrm{ng} /, \mathrm{P}<0.0001)$. The ROC curve analysis showed that total T4 $=1.685 \mu \mathrm{g} /$ had a sensitivity of $62 \%$, specificity of $76 \%$, positive predictive value (PPV) of $71.8 \%$, and negative predictive value(NPV) of $66.7 \%$. Total T3 $=0.82 \mathrm{ng} /$ gavea sensitivity of $91 \%$, specificity of $64 \%$, PPV of $72 \%$, and NPV of $87.8 \%$. Free T4 $=0.01 \mathrm{ng} /$ gave a sensitivity of $51 \%$, specificity of $82 \%$, PPV of $74.2 \%$, and NPV of $62.7 \%$. The best cutoff values were total T4 $=1.685 \mathrm{ng} /$, total $\mathrm{T} 3=0.82 \mathrm{ng} /$, and free $\mathrm{T} 4=0.01 \mathrm{ng} /$.

Conclusions: Detecting total T4, total T3, and free T4 in vaginal washouts of patients suspected of PROM suspected is a simple, available, rapid, and inexpensive method for the diagnosis of PROM. However, a combination of three tests is recommended.
\end{abstract}

Keywords: Diagnosis, Thyroid Hormones, Vaginal Secretions

\section{Background}

Premature rupture of membranes (PROM) and preterm PROM (PPROM) are the rupture of the fetal chorioamniotic membranes before the onset of labor contractions. PROM and PPROM occur in $10 \%$ and $40 \%$ of term and preterm labors, respectively (1). Both conditions are associated with increased risk of maternal and fetal infection, neonatal respiratory distress syndrome, intraventricular hemorrhage, and pulmonary hypoplasia. Early and accurate diagnosis of PROM would allow for proper obstetric intervention and decreased feto-maternal complications. On the other hand, inaccurate diagnosis may lead to unnecessary hospitalization, inappropriate use of antibiotics and corticosteroids, and: unnecessary induction of labor (2).

Patients with PROM usually present with complaint of a sudden large volume of clear fluid leakage. Differential diagnosis includes urinary incontinence and normal vaginal discharge. Concomitant vaginal bleeding, fever, and recent intercourse should be ruled out first.
Then, a sterile speculum examination is performed to evaluate any evidence of fluid pooling in the vagina or leakage from cervical os (3). Traditionally, the diagnosis is continued with a nitrazine paper test, however, this does not have the capability to detect low amounts of amniotic fluid. Absorbent pads (AmnioSense) are able to diagnose low volumes of amniotic fluid due to the longer test duration, but they might cause cytotoxicity and skin irritation, and their accuracy rate is unknown. Both techniques may have false positive results due to contamination with blood, semen, urine, and vaginal inflammation (sensitivity $=90 \%-97 \%$, specificity $=16 \%-$ $70 \%$ ). Microscopic analysis for evidence of ferning of the cervicovaginal discharge is another classic test, with a sensitivity of $51 \%-98 \%$ and specificity of $70 \%-88 \%$, but the results are easily interrupted by the presence of blood, semen, cervical mucus, and fingerprints (4). Amnisure, a placental alpha 1-microglobulin (PAMG-1) assay, is the

Copyright (C) 2015, Shiraz University of Medical Sciences. This is an open-access article distributed under the terms of the Creative Commons Attribution-NonCommercial 4.0 International License (http://creativecommons.org/licenses/by-nc/4.0/) which permits copy and redistribute the material just in noncommercial usages, provided the original work is properly cited. 
latest diagnostic test with excellent accuracy (5), however, it has not yet become popular and widely available, mostly due to the test's complexity and cost. Therefore, there is a great need for an inexpensive, readily available, rapid, and accurate diagnostic test for PROM.

Endocrine system development in the human embryo starts with a thickening in the primitive pharynx, which eventually forms the thyroid gland. The fetus is dependent on maternal thyroid hormones until the age of 12 weeks, when the thyroid gland matures and initiates synthesis of thyroxin independently. The thyroxin level then steadily increases until the age of 34 weeks of gestation. On the other hand, plasma concentrations of T3 are not detectable before the $20^{\text {th }}$ week of gestation, and because of the active metabolism of thyroxin to reverse $\mathrm{T} 3 \mathrm{by}$ the placental and hepatic tissues, the plasma levels of T3 do not reach adult levels, even at term. The fetus' thyroxin plasma levels are closely correlated with gestational age and are lower in preterm neonates as compared to term newborns (6). Recent studies have reported a direct correlation between fetus plasma and amniotic fluid values of thyroid hormones (7). As the chorioamniotic membranes rupture, the intra-amniotic thyroid hormones are released and could be detected in vaginal fluid washout by routine laboratory tests.

\section{Objectives}

Our current study evaluates whether measurement of thyroid hormone concentration in vaginal fluid washout could identify PROM.

\section{Patients and Methods}

The protocol of this study was approved by the Ethical Committee of the Tehran University of Medical Sciences and a written consent was obtained from all patients prior to enrollment. The study was conducted at the department of Obstetrics and Gynecology of ShahidAkbar Abadi Teaching Hospital, Tehran, Iran, from April to March, 2012.

All women with a confirmed diagnosis of PROM, based on direct visualization of amniotic discharge of the cervix at the gestational age of 26 weeks or greater, were included in the study. The rupture of membranes must have occurred less than six hours prior to presentation and not be associated with vaginal bleeding. We excluded patients with sonography-confirmed polyhydramnios or multiple gestations, women with vaginal bleeding, feto-maternal comorbidities (preeclampsia, fetal malformations, placenta previa), and those who had had intercourse within the previous six hours. Of the qualified patients, 45 patients were randomly selected for hormonal analysis. In addition, a group of 45 pregnant women who were matched for maternal age, gestational age, parity, and gravidity were selected from those who were seen during routine prenatal clinic visits. None of the women in the control group had any history or complaint of vaginal discharge. PROM was ruled out in the control group by direct visualization of the cervix via sterile speculum and a negative nitrazine test. Women in both groups had no history of thyroid dysfunction (hypothyroidism, hyperthyroidism, and goiter) and were not taking any thyroid disturbing drugs such as levothyroxine or thioamides.

The age, parity, and gestational age of both groups were recorded. The gestational age was calculated based on the patient's last menstrual period (LMP). To evaluate the vaginal concentrations of thyroid hormones, a speculum-opened vagina was irrigated with $3 \mathrm{ml}$ of normal saline, and then the accumulated fluid was collected using a $5 \mathrm{ml}$ syringe. The collected samples were immediately sent to the laboratory for 10 minutes of centrifuging and hormonal analysis based on electrochemiluminescence (ECL) assay methods.

\subsection{Statistics}

Statistical analysis was performed using SPSS version 19 software (SPSS Inc., Chicago, IL, USA). Results are presented as mean \pm standard deviation. To compare the levels of thyroid hormones, the Student's t-test was used. The receiver-operating characteristic (ROC) curve analysis was used for test accuracy determination. A P value less than 0.05 was considered significant.

\section{Results}

The control subjects were matched to the patients in the study group with respect to maternal age, gestational age, and parity. Table 1 summarizes the demographic and obstetric characteristics of the patients with PROM and the controls.

The mean total $\mathrm{T} 4$ concentration in patients with PROM and normal pregnant women were $2.1 \pm 1.3 \mu \mathrm{g} / \mathrm{mL}$ and $1.55 \pm 0.58 \mu \mathrm{g} / \mathrm{mL}$, respectively $(\mathrm{P}=0.01)$. Total vaginal T3 levels in the PROM group were significantly higher compared to normal pregnant women $(1.28 \pm 0.42$ $\mathrm{ng} / \mathrm{mL}$ vs. $0.8 \pm 0.26 \mathrm{ng} / \mathrm{mL}, \mathrm{P}<0.0001)$. Also, the free T4 level was significantly higher in women with PROM as compared with normal pregnant women (0.026 \pm $0.034 \mathrm{ng} / \mathrm{mL}$ vs. $0.007 \pm 0.004 \mathrm{ng} / \mathrm{mL}, \mathrm{P}<0.0001)$. Table 2 demonstrates the mean concentrations of total $\mathrm{T} 4$, total T3, and free T4 in both groups. The concentration ranges of total $\mathrm{T} 4$, total $\mathrm{T} 3$, and free $\mathrm{T} 4$ in patients with PROM and the controls were $0.13-5.23$ vs. $0.46-3.95 \mu \mathrm{g} /$ $\mathrm{mL}, 0.37-2.28$ vs. $0.24-1.81 \mathrm{ng} / \mathrm{mL}$, and $0-0.14$ vs. $0-$ $0.02 \mathrm{ng} / \mathrm{mL}$, respectively.

As Figure 1 shows, the ROC curve analysis showed that total $\mathrm{T} 4=1.685 \mathrm{ng} / \mathrm{mL}$ was the best cutoff value, with a sensitivity of $62 \%$, specificity of $76 \%$, positive predictive value (PPV) of $71.8 \%$, and negative predictive value (NPV) of $66.7 \%$.

Also, the ROC curve analysis showed that total T3 $=0.82$ $\mathrm{ng} / \mathrm{mL}$ was the best cutoff value, with a sensitivity of $91 \%$, specificity of $64 \%$, PPV of $72 \%$, and NPV of $87.8 \%$ (Figure 2 ).

Additionally, the ROC curve analysis showed that free $\mathrm{T} 4=$ $0.01 \mathrm{ng} / \mathrm{mL}$ was the best cutoff value, with a sensitivity of $51 \%$, specificity of $82 \%$, PPV of $74.2 \%$, and NPV of $62.7 \%$ (Figure 3 ). 
Rashidi M et al.

Table 1. Comparison of the Demographic and Obstetric Characteristics of Patients with PROM and Controls $(\mathrm{N}=45)^{\mathrm{a}}$

\begin{tabular}{lccc}
\hline & Patients With PROM & Normal Pregnant Women & P Value \\
\hline Maternal Age, $\mathbf{y}$ & $25 \pm 4.8$ & $25 \pm 4.6$ & .9 \\
Gestational Age, $\mathbf{y}$ & $34 \pm 3.4$ & $33 \pm 3.5$ & .5 \\
\hline Parity & & & .3 \\
\hline Nulliparous & $25(55.6)$ & $20(44.4)$ & $25(55.6)$ \\
\hline \multicolumn{1}{c}{ Multiparous } & $20(44.4)$ &
\end{tabular}

${ }^{\mathrm{a}}$ Data are presentedas mean \pm SD or No.(\%).

Table 2. Comparison of the Thyroid Hormone Levels in Patients with PROM and Normal Pregnant Women ${ }^{\mathrm{a}}$

\begin{tabular}{lccc}
\hline & Patients With PROM & Normal Pregnant Women & P Value \\
\hline Total T4, $\mathrm{ng} / \mathrm{ml}$ & $2.1 \pm 1.3$ & $1.55 \pm 0.58$ & .01 \\
Total T3, ng/mL & $1.28 \pm 0.42$ & $0.8 \pm 0.26$ & .0001 \\
\hline Free T4, ng/mL & $0.026 \pm 0.034$ & $0.007 \pm 0.004$ & .0001 \\
\hline
\end{tabular}

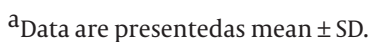

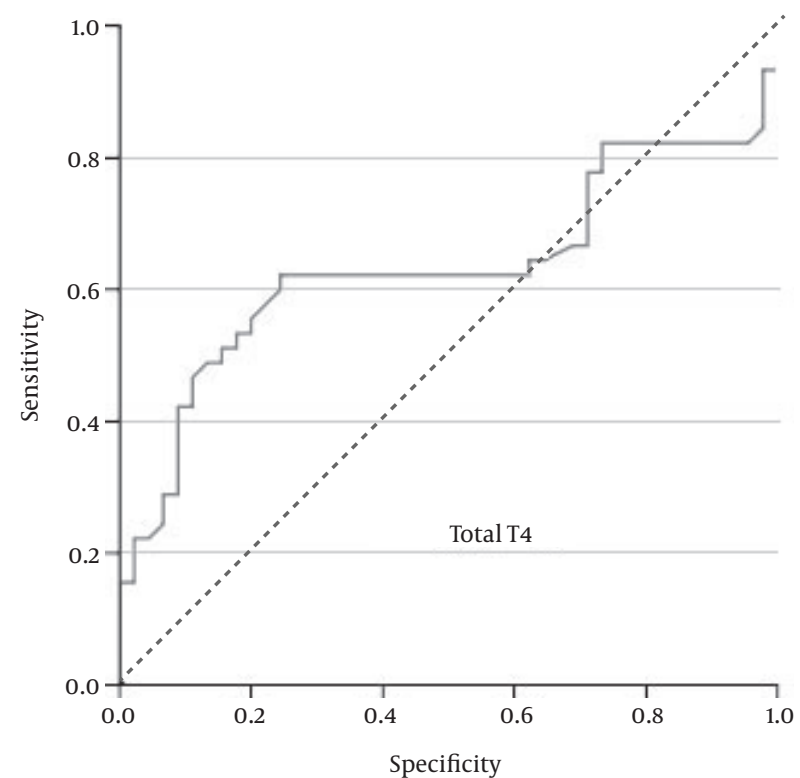

Figure 1. Receiver-operating Characteristic (ROC) Curve for Total T4 Concentration

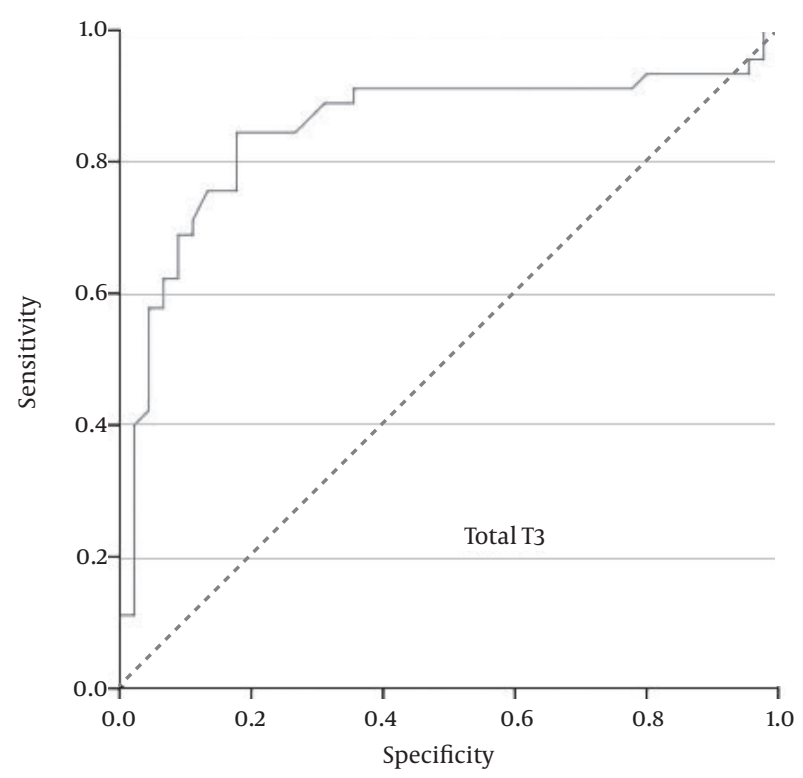

Figure 2. ROC Curve for Total T3 Concentration 
Rashidi M et al.

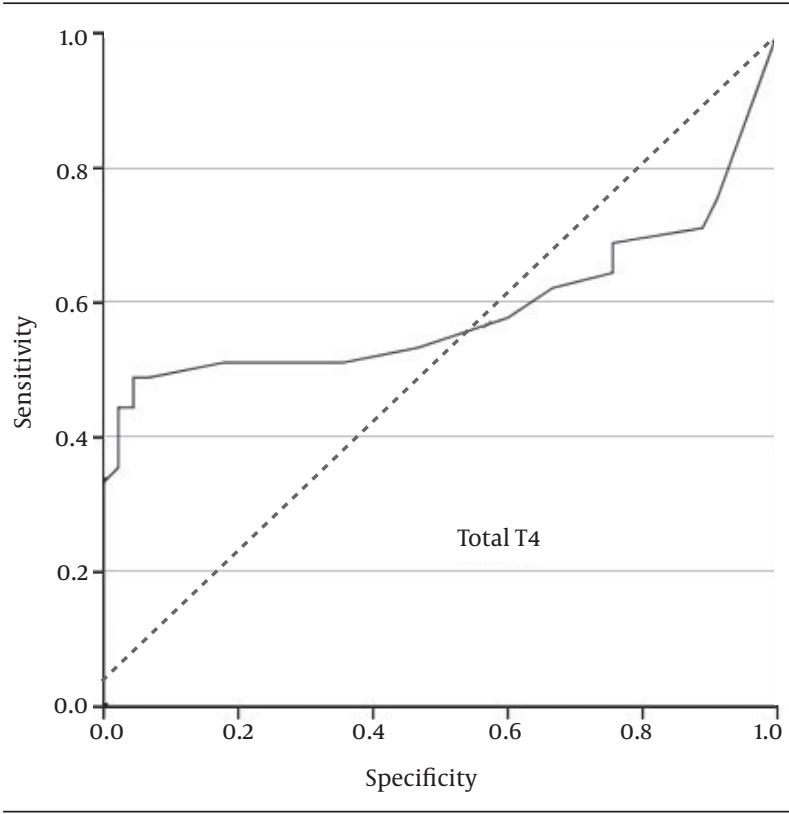

Figure 3. ROC Curve for Free T4 Concentration

\section{Discussion}

The results of the current study demonstrated that the vaginal concentrations of total T4, total T3, and free T4 of patients with PROM is significantly higher than normal pregnant women. Moreover, the ROC curve analysis revealed that none of these measures alone has the desired accuracy for the diagnosis of PROM in suspected patients. However, in combination these three hormonal analyses could be an easy, readily available, and rapid diagnostic test. The best cutoff values we achieved were total T4 = $1.685 \mathrm{ng} / \mathrm{mL}$, total T3 $=0.82 \mathrm{ng} / \mathrm{mL}$, and free $\mathrm{T} 4=0.01 \mathrm{ng} / \mathrm{mL}$. In a similar study by Kale et al. (8), the vaginal concentrations of total T4, total T3 and free T4 were compared between normal pregnancies and PPROM between 26-36 weeks of gestation. The vaginal total and free $\mathrm{T} 3 \mathrm{l}$ levels were not statistically different between the patients and the controls, but vaginal total T4 and free T4 levels were significantly higher in the PPROM group. This study concluded that the optimal cutoff value for total T4 $(0.866 \mu \mathrm{g} / \mathrm{dL}) \mathrm{had}$ sensitivity of $83.3 \%$, specificity of $60.0 \%$, PPV of $67.6 \%$, and NPV of $78.3 \%$. Free $\mathrm{T} 4=0.079 \mathrm{ng} / \mathrm{dL}$ gave a sensitivity of $90 \%$, specificity of $70.0 \%$, PPV of $75 \%$, and NPV of $87.5 \%$. These hormonal concentrations for total T4 (sensitivity of $84.4 \%$ with negligible specificity) and free T4 (specificity of $100 \%$ with negligible sensitivity) in our results were not clinically practical. Instead, measuring of total T3 in our study was the most accurate diagnostic test.

Farag and colleagues, in a case control study, evaluated the diagnostic value of vaginal fluid free T3 and free T4 in women with PPROM. They showed vaginal fluid free T3 and free $\mathrm{T} 4$ seemed to be useful and simple markers in the diagnosis of PPROM. Sensitivity, specificity, and positive and negative predictive values for free T3 (cutoff, 1.06 $\mathrm{pg} / \mathrm{mL}$ ) were $88 \%, 70 \%, 74.6 \%$, and $85.4 \%$, respectively, while those for free T4 (cutoff $0.063 \mathrm{ng} / \mathrm{dL}$ ) were $86 \%, 72 \%, 75.4 \%$, and $83.7 \%$, respectively (9).

The thyroid hormones in vaginal washout could have maternal or fetal origin. Considering hormonal reference values in vaginal secretions is helpful to determine the major source of thyroid hormones. Surprisingly, previous studies have analyzed the thyroid hormonal concentrations in amniotic fluid. In a study by Singh et al. (10), the reference intervals for fetal thyroid status in amniotic fluid have been reported as: TSH less than $0.1-0.5$ $\mathrm{mU} / \mathrm{L}$ (median=0.1 mU/L), total T4 2.3 - 3.9 $\mu \mathrm{g} / \mathrm{dL}$ (median $=3.3 \mu \mathrm{g} / \mathrm{dL}$ ), and free $\mathrm{T} 4$ less than $0.4-0.7 \mathrm{ng} / \mathrm{dL}$ (median = $0.4 \mathrm{ng} / \mathrm{dL}$ ). A similar study by Baumann et al. (7) reported the reference intervals of the thyroid hormones in amniotic fluid as TSH $=0.04-0.51 \mu \mathrm{IU} / \mathrm{mL}$ (median $=0.10$ $\mu \mathrm{IU} / \mathrm{mL}$ ) and free T4 less than $0.10-0.77 \mathrm{ng} / \mathrm{dL}$ (median $=0.26 \mathrm{ng} / \mathrm{dL}$ ). When we compare the results of thyroxin values in vaginal washouts of patients with PROM with reference intervals in amniotic fluid, the fetal origin of thyroxin due to rupture of chorioamniotic membranes shows higher probability.

Recent studies have investigated the accuracy of new biomarkers; among them insulin-like growth factorbinding protein-1 (IGFBP-1) (11), IL-8 and Annexin A2 (12), and placental alpha 1-microglobulin (PAMG-1) have shown promising results. IGFBP-1 has a sensitivity of $87.5 \%$, specificity of $94.4 \%$, PPV of $92.1 \%$, and NPV of $91.1 \%$ (13), although heavy vaginal bleeding and prolonged cessation of leakage might give false positive and negative results, respectively (14). Amnisure (PAMG-1 assay) is a bedside strip test with a sensitivity of $98.9 \%$, specificity of $100 \%$, a PPV of $100 \%$, and an NPV of $99.1 \%$ (5), but its positive results should be interpreted cautiously, because the clinical significance of a positive test due to micro-leakage of amniotic fluid is not yet clear $(15,16)$. There is not enough evidence in the literature to favor one of these two new biomarkers (17). Thus, extensive investigations are being carried out on other biological markers $(5,18)$.

Measuring thyroid hormone concentrations in vaginal fluid washouts has some advantages. First, it does not require any additional diagnostic laboratory instruments or specially educated personnel and is easily performed with available kits. Second, the procedure is comparably inexpensive and quick. And third, it measures three thyroid hormone values simultaneously. However, as far as we know only one study has evaluated the diagnostic accuracy of thyroid hormonal concentrations in vaginal fluid washout, so far. So, in this study we added additional measurements of this new diagnostic method.

One limitation of our study was that the maternal thyroid status was not evaluated before measuring the vaginal concentrations, so subclinical hypothyroidism or hyperthyroidism in the sample might influence the final results. The same situation is true for neonates, because they were not followed for delayed thyroid dysfunction. Also, it is not yet clear whether sample contamination 
with blood, semen, and bacterial colonies could create false positive or false negative results. Future studies are needed to further clarify the diagnostic accuracy of this method in various clinical settings.

Measuring vaginal concentrations of total T4, total T3, and free T4 alone does not have enough accuracy for detecting suspected cases of PROM, but a combination of all three tests could be useful. Further studies are needed to clarify the capabilities of thyroid hormone diagnostics in suspected cases of PROM.

\section{Footnote}

Authors' Contribution:All authors contributed in designing, data collection and writing of the manuscript.

\section{References}

1. Moore RM, Mansour JM, Redline RW, Mercer BM, Moore JJ. The physiology of fetal membrane rupture: insight gained from the determination of physical properties. Placenta. 2006;27(1112):1037-51. doi: 10.1016/j.placenta.2006.01.002. [PubMed: 16516962]

2. Caughey AB, Robinson JN, Norwitz ER. Contemporary diagnosis and management of preterm premature rupture of membranes. Rev Obstet Gynecol. 2008;1(1):11-22. [PubMed:18701929]

3. Medina TM, Hill DA. Preterm premature rupture of membranes: diagnosis and management. Am Fam Physician. 2006;73(4):65964. [PubMed:16506709]

4. Di Renzo GC, Roura LC, Facchinetti F, Antsaklis A, Breborowicz G Gratacos E, et al. Guidelines for the management of spontaneous preterm labor: identification of spontaneous preterm labor, diagnosis of preterm premature rupture of membranes, and preventive tools for preterm birth. J Matern Fetal Neonatal Med. 2011;24(5):659-67. doi: 10.3109/14767058.2011.553694. [PubMed: 21366393]

5. Cousins LM, Smok DP, Lovett SM, Poeltler DM. AmniSure placental alpha microglobulin-1 rapid immunoassay versus standard diagnostic methods for detection of rupture of membranes. Am J Perinatol. 2005;22(6):317-20. doi: 10.1055/s-2005-870896. [PubMed: 16118720$]$

6. Kratzsch J, Pulzer F. Thyroid gland development and defects. Best Pract Res Clin Endocrinol Metab. 2008;22(1):57-75. doi: 10.1016/j. beem.2007.08.006. [PubMed:18279780]

7. Baumann NA, Gronowski AM. Establishment of reference intervals for thyroid-stimulating hormone and free thyroxine in amniotic fluid using the Bayer ADVIA Centaur. Am J Clin Pathol. 2007;128(1):158-63. doi: 10.1309/69A5AV266W230AUA. [PubMed: $17580284]$
8. Kale A, Kale E, Akdeniz N, Kuyumcuoglu U, Canoruc N. Proposal of a diagnostic test for the detection of preterm premature rupture of membranes based on the determination of thyroid hormones in vaginal washing fluid. Fetal Diagn Ther. 2007;22(5):330-4. doi: 10.1159/000103290. [PubMed: 17556818]

9. Farag AH, Elghetany SS, Elkashif MS. Aspartate aminotransferase and free thyroid hormones in vaginal washing fluid as markers for preterm pre-labor rupture of membranes. J Obstet Gynaecol Res. 2015;41(9):1352-6. doi: 10.1111/jog.12730. [PubMed: 26014210]

10. Singh PK, Parvin CA, Gronowski AM. Establishment of reference intervals for markers of fetal thyroid status in amniotic fluid. $J$ Clin Endocrinol Metab. 2003;88(9):4175-9. doi: 10.1210/jc.2003030522. [PubMed:12970283]

11. Abdelazim IA. Insulin-like growth factor binding protein-1 (Actim PROM test) for detection of premature rupture of fetal membranes. J Obstet Gynaecol Res. 2014;40(4):961-7. doi: 10.1111/ jog.12296. [PubMed:24612210]

12. Jia X. Value of amniotic fluid IL-8 and Annexin A2 in prediction of preterm delivery in preterm labor and preterm premature rupture of membranes. J Reprod Med. 2014;59(3-4):154-60. [PubMed: 24724224]

13. Tagore S, Kwek K. Comparative analysis of insulin-like growth factor binding protein-1 (IGFBP-1), placental alpha-microglobulin-1 (PAMG-1) and nitrazine test to diagnose premature rupture of membranes in pregnancy. J Perinat Med. 2010;38(6):609-12. doi:10.1515/JPM.2010.099. [PubMed: 20707623]

14. Akercan F, Cirpan T, Kazandi M, Terek MC, Mgoyi L, Ozkinay E. The value of the insulin-like growth factor binding protein-1 in the cervical-vaginal secretion detected by immunochromatographic dipstick test in the prediction of delivery in women with clinically unconfirmed preterm premature rupture of membranes. Eur J Obstet Gynecol Reprod Biol. 2005;121(2):159-63. doi: 10.1016/j. ejogrb.2004.12.006. [PubMed:16054956]

15. Lee SM, Lee J, Seong HS, Lee SE, Park JS, Romero R, et al. The clinical significance of a positive Amnisure test in women with term labor with intact membranes. J Matern Fetal Neonatal Med. 2009;22(4):305-10. doi: 10.1080/14767050902801694. [PubMed: 19350444]

16. Lee SM, Romero R, Park JW, Kim SM, Park CW, Korzeniewski SJ, et al. The clinical significance of a positive Amnisure test in women with preterm labor and intact membranes. J Matern Fetal Neonatal Med. 2012;25(9):1690-8. doi: 10.3109/14767058.2012.657279. [PubMed: 22280400]

17. Gallot D, Guibourdenche J, Sapin V, Goffinet F, Doret M, Langer B et al. [Which biological test to confirm rupture of membranes?]. J Gynecol Obstet Biol Reprod (Paris). 2012;41(2):115-21. doi: 10.1016/j. jgyn.2011.12.001. [PubMed: 22227234]

18. van der Ham DP, van Melick MJ, Smits L, Nijhuis JG, Weiner CP, van Beek JH, et al. Methods for the diagnosis of rupture of the fetal membranes in equivocal cases: a systematic review. Eur J Obstet Gynecol Reprod Biol. 2011;157(2):123-7. doi: 10.1016/j. ejogrb.2011.03.006. [PubMed: 21482018] 